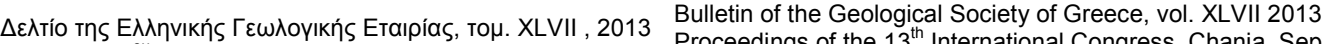

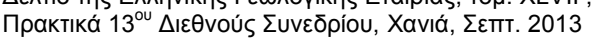
2013

\title{
FLOOD AND GROUNDWATER MANAGEMENT FOR THE MOUNTAIN PLATEAU OF OMALOS BASED ON GEOINFORMATICS TECHNIQUES
}

\author{
Kourgialas N.N. ${ }^{1}$ and Karatzas G.P. ${ }^{1}$ \\ ${ }^{l}$ Department of Environmental Engineering, Technical University of Crete, Greece, \\ nektarios.kourgialas@enveng.tuc.gr; karatzas@mred.tuc.gr
}

\begin{abstract}
A viable approach for flood and groundwater management in a mountain Plateau based on geoinformatics techniques is presented in this work. The proposed water management plan has two components: (a) the determination of the flood-hazard areas, and (b) the estimation of groundwater flow. For the first component, six factors were considered in order to estimate the spatial distribution of the flood hazardous areas: elevation, slope, land use, rainfall intensity, geology, and flow accumulation, The study area was divided into five regions characterized by different degrees of flood hazard ranging from very low to very high. The produced map of flood-hazard areas identifies the areas at high risk of flooding. The second component includes a groundwater management approach for estimating groundwater flow and the potential contamination risk. The proposed methodology can be used to objectively compare different scenarios based on anthropogenic interventions that can affect the flood-prone areas or the groundwater flow dynamic. All these approaches were applied at the Omalos Plateau in the White Mountains of Crete in Greece.
\end{abstract}

Key words: flood-hazard areas, GIS, groundwater hazard management, Omalos Plateau.

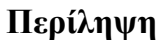

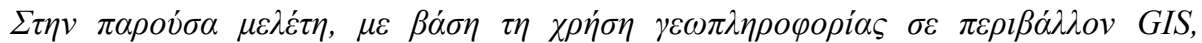

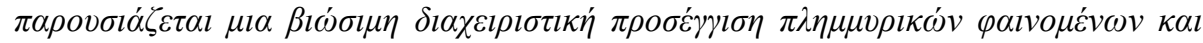

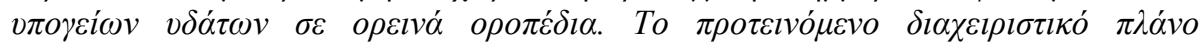

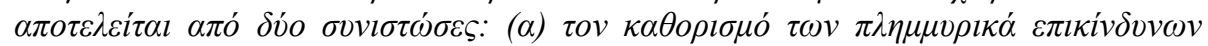

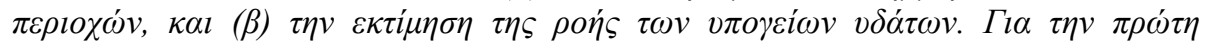

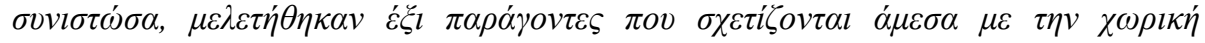

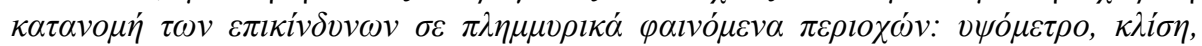

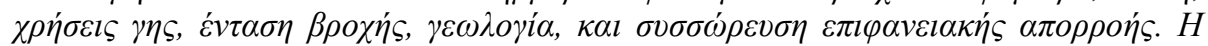

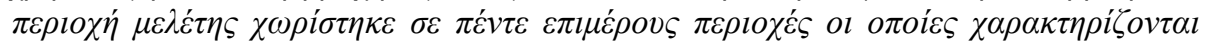

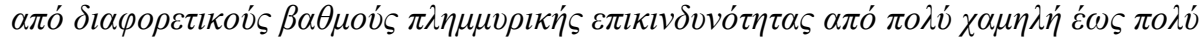

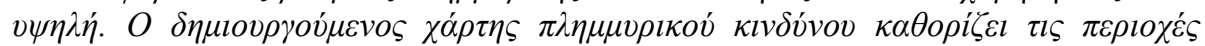

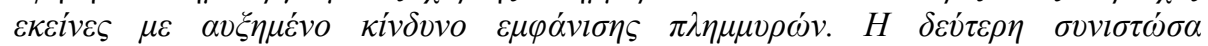

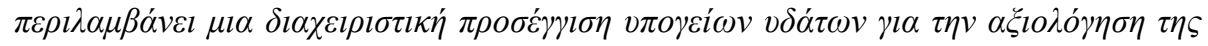

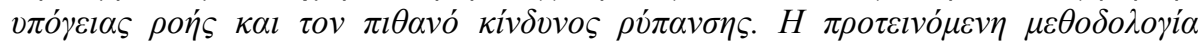

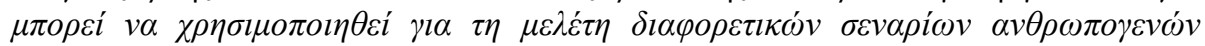

XLVII. No $2-721$ 


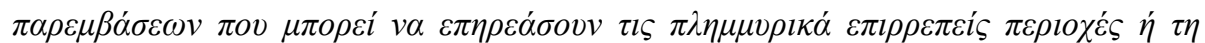

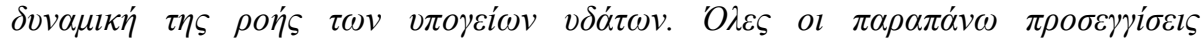

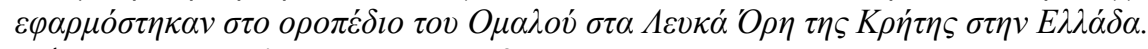

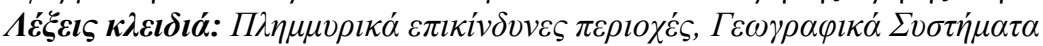

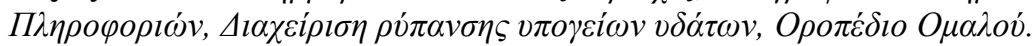

\section{Introduction}

The number of flash flood events has increased significantly all around the world over the last three decades. Especially, in mountainous areas flash floods are very common where rapid snowmelt or heavy rainfalls are quickly transformed into runoff. These events, due to the high capacity of transport, can be characterized as the most significant weather-related hazards in many mountain Plateaus all around the world, causing considerable economic and human losses (Ballesteros et al. 2010). The main causes of flash floods are climatic changes, changes in land use and other anthropogenic interventions. The most common anthropogenic interventions are urban growth, the partial or total cover of torrent banks, watercourse alignment, improperly dimensioned bridges, deforestation and the consequent erosion, the construction of roads or other structures across the watercourse, subsidence observed in flat regions due to anthropogenic interventions such as overpumping, and finally, the change or deviation of the watercourse (Kourgialas and Karatzas 2011).

In addition, in mountain Plateaus the role of groundwater management is very important. Specifically, hydrogeologic settings in Mediterranean mountain areas are typically characterized by the occurrence of fractured-rock aquifers (Wireman 2003). As the population density and agricultural activity increases in these fractured-rock settings the management of groundwater supplies becomes a very crucial issue. In addition, in these regions there has been an increase in anthropogenic contamination of groundwater resources. As a result of this increasing stress on water resources in these mountain regions, groundwater scientists have recognized the need to develop easy to handle methods and tools for characterizing groundwater contaminant transport risk.

The availability of detailed climatic and hydrogeological data in mountain regions is in general limited hindering the use a detail modelling approach. Thus, in flash floods studies, precipitation records and flow data have been widely used (Chiang and Chang 2009); however, the use of systematic data on flash floods presents several challenges in mountainous catchments as representative instrumental records are not normally available in these environments (Ballesteros et al. 2010). Thus, in ungauged mountainous areas where expensive and time consuming hydrological-hydraulic simulations are not possible the use of an effective Geographic Information Systems (GIS) management tool is essential to delineate the flood prone areas (Manfreda et al. 2008). Furthermore, the synthesis of available data and the mapping of the relationships between groundwater hazard and the elements at risk require the use of tools such as GIS. Nowadays, integrated approaches of GIS and remote sensing technology are capable of providing the base for quantitative analysis of an environmental process with an appropriate degree of accuracy.

The aim of this work is to present an integrated and easy to handle GIS tool that incorporates geoinformatics techniques for flood and groundwater management in mountain Plateau. The proposed water management tool has two components: (a) the determination of the flood-hazard areas, and (b) the estimation of groundwater flow and the potential contamination risk under current and future anthropogenic pressures and activities. All these approaches were applied at the Omalos Plateau in the White Mountains of Crete in Greece. 


\section{The Study Area}

The Omalos Plateau is the largest active polje of Western Crete (Greece) and covers an area of approximately $6 \mathrm{~km}^{2}(3 \times 2 \mathrm{~km})$. The elevations of this Plateau range from 1032 to $1360 \mathrm{~m}$ above sea level within the boundaries of the Natura 2000 site 'Lefka Ori' (GR 4340008) (Figure 1). The mean annual temperature is $9.3{ }^{\circ} \mathrm{C}$ and monthly means range from $2.2{ }^{\circ} \mathrm{C}$ in January to $19.3{ }^{\circ} \mathrm{C}$ in July (data from the period 1994 to 2012 from the meteorological station of Omalos plain). The mean annual rainfall for that period is $1600 \mathrm{~mm}$. The Plateau consists of Post-Mesozoic sediments (recent deposits) which lie on the "Trypali" metamorphic carbonates and the Plattenkalk carbonate group. The later formations are karstified at Omalos. The term karstification refers to geological processes mainly involving dissolution. These processes create unique morphological characteristics such as dolines, whose size varies from several meters to few hundreds of meters, or a polje which often results from more than one dolines or karstic structures (Hamdan et al. 2012). The Omalos plain is both cultivated with cereals and fruit trees and grazed by sheep and goats. As the anthropogenic innervations and agriculture, in the study area, have become more intensive a proper management plan regarding the flood phenomena and the protection of groundwater supplies is a challenge.

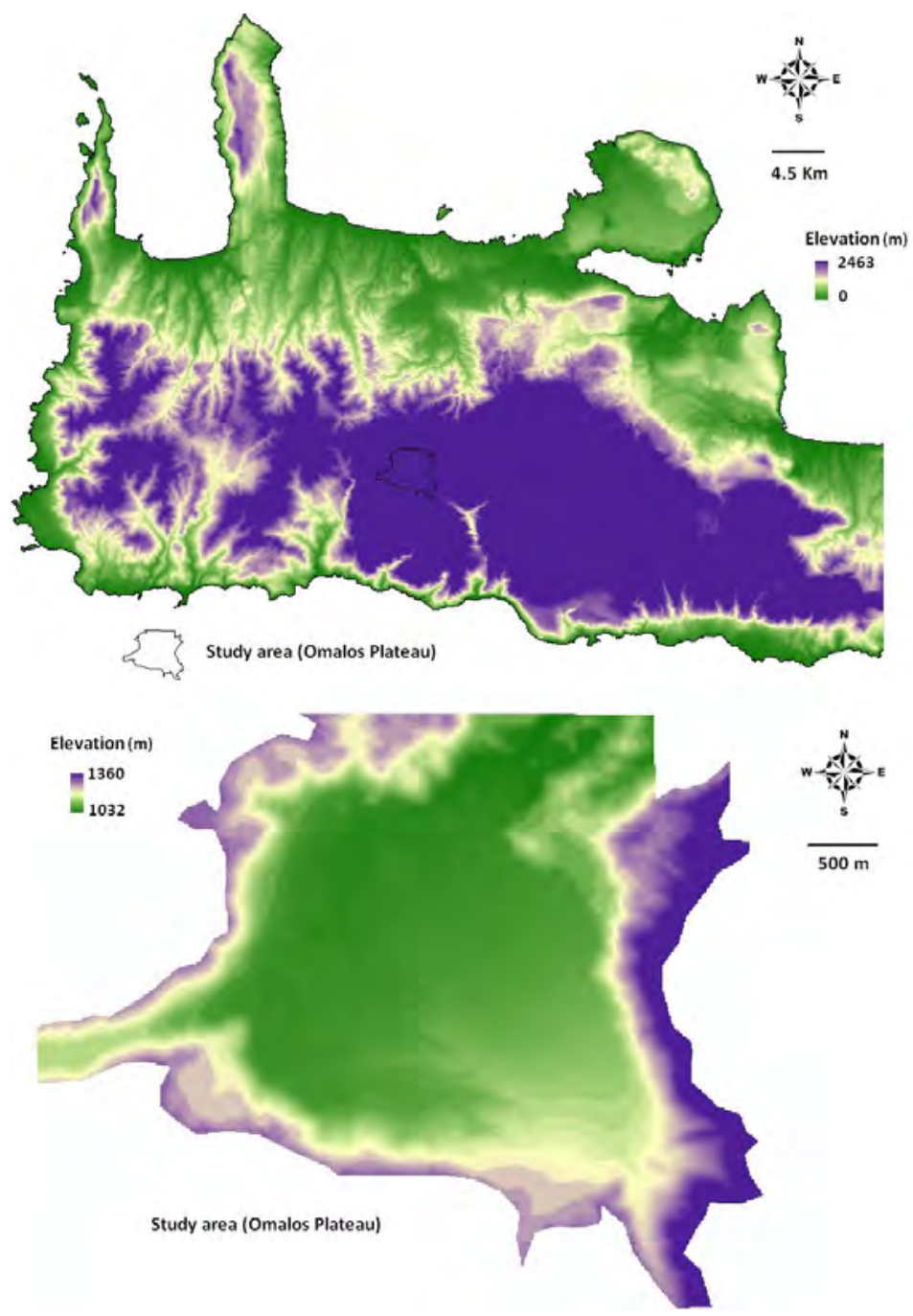

Figure 1 - Topography of the study area (Omalos Plateau).

XLVII. No $2-723$ 


\section{Materials and Methods}

\subsection{Estimating the Flood Hazardous Areas in the Omalos Plateau}

In order to estimate the flood hazardous areas the study area was divided into five regions characterized by different degrees of flood hazard (very high, high, moderate, low and very low). This classification is performed by considering the factors that form and influence a flood and by assigning relative weights to them. This process is performed in a Geographic Information Systems (GIS) environment and thematic maps are produced for each parameter. The linear combination of the thematic maps and the selection of the weights yield the final map of flood hazardous areas.

For the estimation of the flood hazardous areas in the Omalos Plateau, six (6) thematic maps were created using GIS Arc Map environment: elevation, slope, land use, rainfall intensity, geology, and flow accumulation. The factors used in this study were selected due to their general relevance to the flood hazards and according to literature surveys (Yahaya et al. 2010; Kourgialas and Karatzas 2011). All of these maps were georeferenced to the Greek Coordinate System EGSA'87. The produced raster maps were $10 \times 10 \mathrm{~m}$, i.e., a $100 \mathrm{~m}^{2}$ raster unit.

The original data include the topographic maps (1:5000) and the monthly rainfall values from seven stations located in the surrounding area. The Digital Elevation Model (DEM) for the terrain was first created by using the 3D Analyst tool. Corine 2006 and remote sensing methods (aerial photographs) were used to determine the land use map, while the traditional field explorative geological mapping was used to determine the geological map of the Omalos Plateau. The DEM was used to determine the flow direction in each raster cell. This process was followed by the ident ification of the water accumulation points. The flow concentration map, which indicates the number of cells that hydrologically contribute to each raster cell was developed by using the flow direction map combined with a suitable algorithm (flow accumulation - Arc Hydro). Output cells with a high flow accumulation (pixels) are areas of concentrated flow (Kourgialas and Karatzas 2011).

In order to determine the rainfall intensity, the meteorological data of seven meteorological station $\mathrm{s}$ in the surrounding area of the Omalos Plateau, shown in Figure 2, were used. Specifically, the recorded meteorological data from stations M1, M2, M3, and M6 was for the period 1999-2011, from station M7 the period was 1960-2010, while for stations M4 and M5 the time period was 2007-2012. The rainfall intensity map was created by using the Modified Fournier Index methodology (Morgan 2005):

$$
M F I=\sum_{1}^{12} \frac{p^{2}}{P}
$$

where MFI: the Modified Fournier Index, $\sum_{1}^{12}$ : the 12-month summation, $p$ : the average monthly rainfall, and $P$ : the average annual rainfall.

The MFI indicator expresses the sum of the average monthly rainfall intensity at a station. In the present study, at each station the territorial contribution of the MFI index values were considered using the spline interpolation method (Kourgialas and Karatzas 2011).

\subsection{Estimating the Groundwater Direction and Groundwater Contamination Risk in the Omalos Plateau}

For estimating the groundwater contamination risk in the extended area of the Omalos Plateau the equipotential contours map was created in a GIS environment. This map describes the groundwater flow direction in the study area. Combining this information with the recorded faults 
in the extended area of the Omalos Plateau the groundwater hazard can be estimated. The original data for the creation of the above maps include: a) land uses based on Corine 2006 and aerial photographs, b) hydrogeological layers maps, c) soil maps, and d) groundwater level data from wells in the study area. Specifically, in this study the recorded groundwater level data was obtained from four wells for the time period 2004-2012 (Figure 3). These data was the only available from the Omalos Plateau.

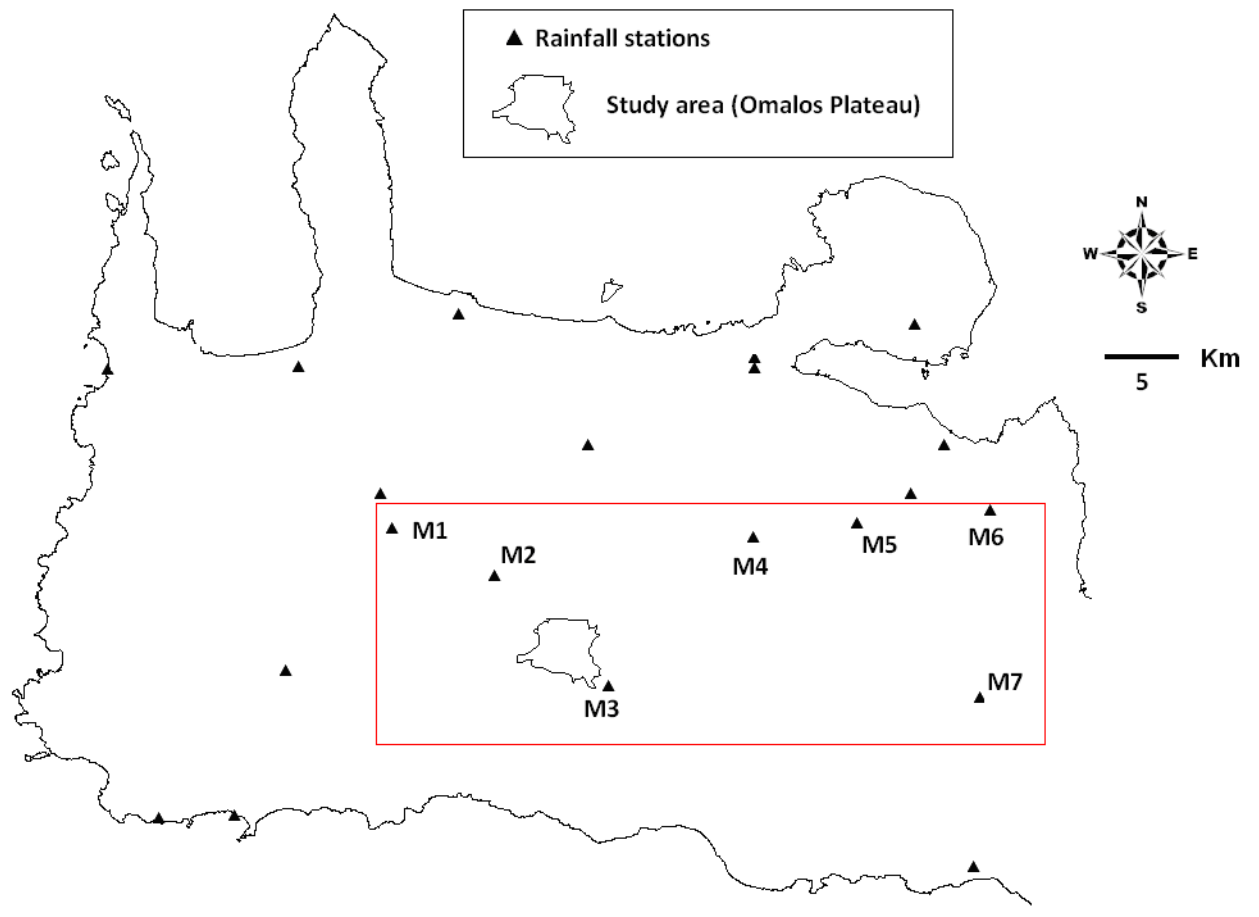

Figure 2 - Locations of the Meteorological stations.

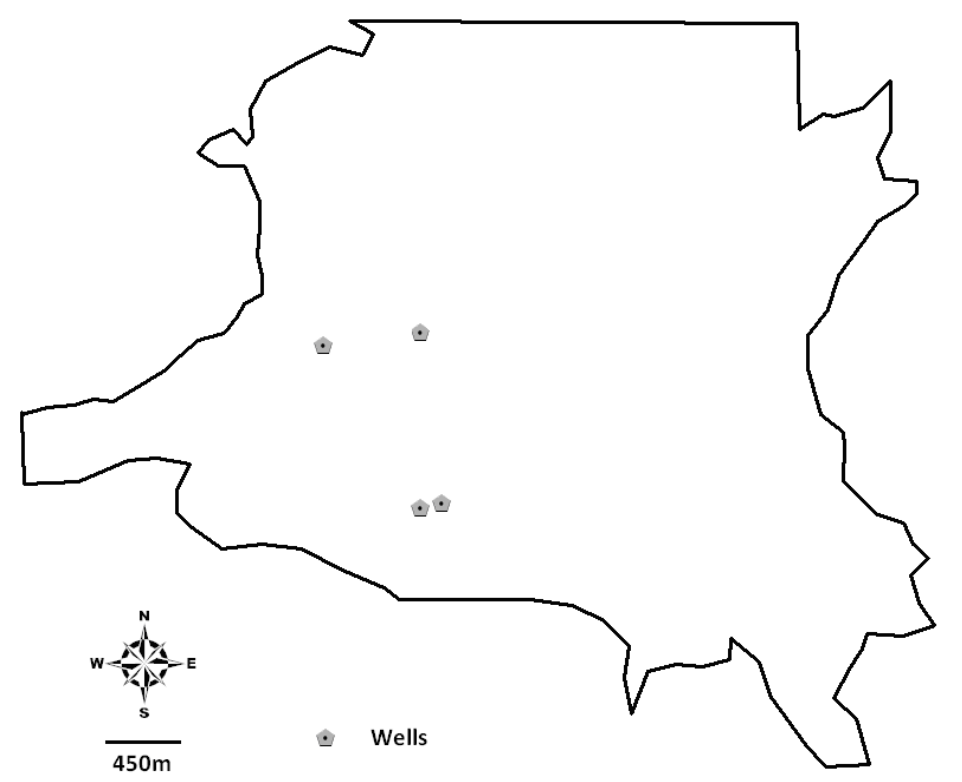

Figure 3 - Observation well locations.

$\underline{\text { XLVII, No } 2-725}$ 


\section{Results and Discussion}

\subsection{Flood Prone Areas}

The six factors introduced in section 3.1 were used to estimate the flood hazardous areas and create the corresponding map. The effect of each factor is mapped as five different hazard levels: very high (20-year flood), high (100-year flood), moderate (200-year flood), low (500-year flood), and very low ( $>500$-year flood). Among these factors, flow accumulation, slope, elevation and rain fall intensity have numeric values, whereas geology and land use are expressed in descriptive form . In the case of the numeric-valued factors, five different hazard classes were identified on the base s of the Jenk's Natural Breaks classification (Smith 1986). In the case of the non numeric-valued factors, classification depends mainly on the influence of the factor on the generation of flood process. For instance, for the geology factor, a karstic geology indicates a very low flood hazard. In the case of the land use factor, limited land cover (low land cover percentage) indicates a very high flood hazard.

The flood hazardous areas cannot be estimated by considering the effect of each factor separately. The integration of all factors is necessary in order to obtain the overall flood hazardous areas map. Since all factors do not have the same degree of influence on the hazardous areas, a weighting approach, where a different weight is assigned to each factor, was applied while the factor weights were determined by employing the methodology presented by Kourgialas and Karatzas (2011). Based on this methodology, the effects of each factor on all other factors are depicted in Figure 4. A solid line between two factors indicates that one factor has a main effect on the other pointed by the arrow, that is, a change of the first factor has a direct effect on the other (main avenue). A dashed line between two factors indicates that one factor has a secondary effect on the factor pointed by the arrow, that is, a change of the first factor has an indirect effect on the other (minor avenue). For example, flow accumulation has a main effect on land use and a secondary effect on slope. In order to quantify the two different types of effects, one (1) point is assigned to a main effect and half a point (1/2) to a secondary (Shaban et al. 2006). Then, the rate for a factor is computed as the summation of the points corresponding to the effects emanating from the factor.

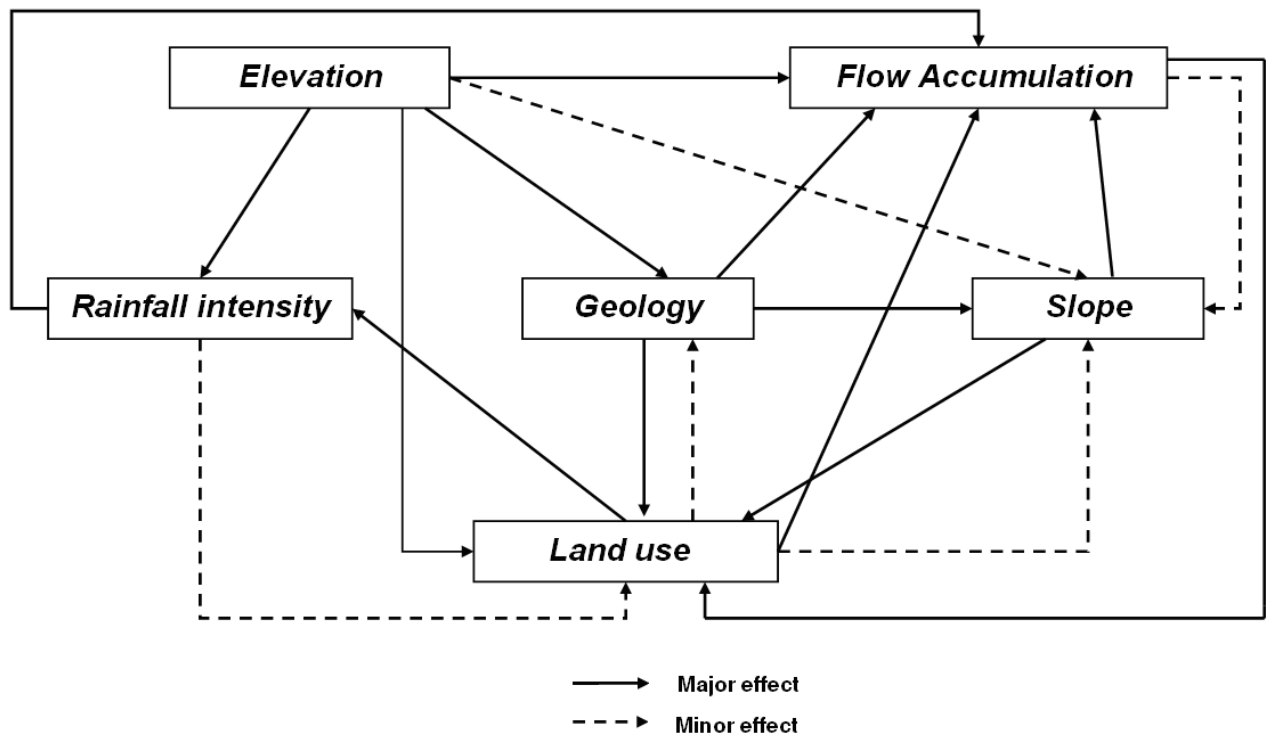

Figure 4 - A schematic depiction of the interaction between factors that influence the flood hazard (Kourgialas and Karatzas 2011).

$\underline{\text { XLVII. No } 2-726}$ 
Based on the above weighting approach and according to Kourgialas and Karatzas (2011) the contribution of each factor to the flood hazardous areas, expressed as a percentage, is for the elevation: $31.49 \%$, slope: $14 \%$, land use: $21 \%$, rainfall intensity: $10.5 \%$, geology: $12.52 \%$, and flow accumulation: $10.5 \%$.

The resulting map of hazardous areas includes the combination of the above six variables that are related directly to any flood event that occurs in the area of study. Specifically, the six maps that were developed after the classification method (Figure 5) were combined using a weighted linear combination approach in a GIS environment.

According to this technique each factor is multiplied by its percentage weight and the summation of all factors yields the final hazardous areas map (Shaban et al. 2006):

$$
S=\sum w_{i} x_{i}
$$

where, $S$ is the final hazardous areas map, $w_{i}$ is the weight of factor $i$ (percentage) and $x_{i}$ is the rate of the factor $i$.

The factors (maps) were combined according to Equation (2) and the final flood hazardous areas map was produced (Figure 6). According to this figure, the study area of Omalos Plateau can be classified with respect to flood hazard from high to very low. Based on the results, the south-east parts of the Omalos Plateau can be characterized as high flood prone areas.

\subsection{Groundwater Risk under an Intensive Agriculture}

Nowadays, due to intensive agricultural activities in the study area, of particular interest is the hypothetical scenario of charging pollutants (e.g. fertilizers, pesticides) and whether it may create environmental problems in the extended area.

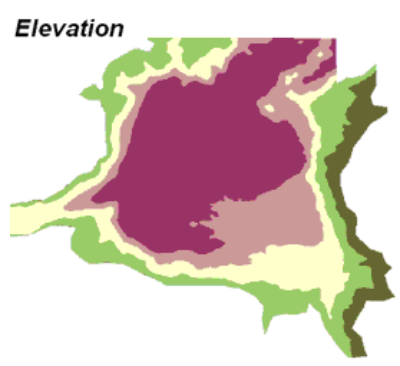

Rainfall intensity

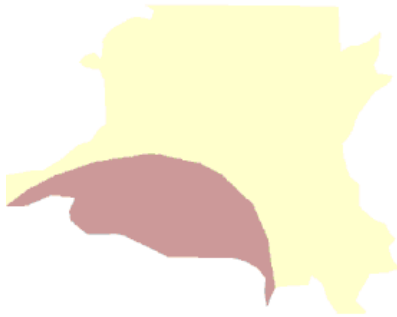

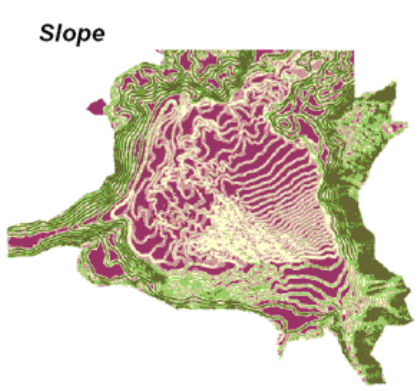

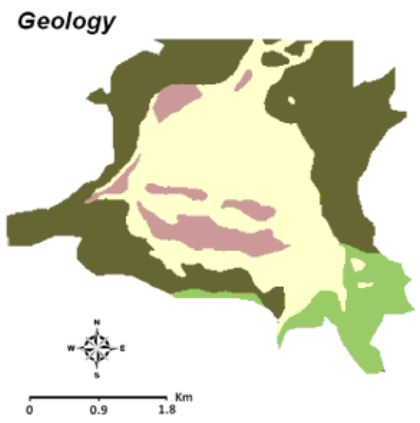

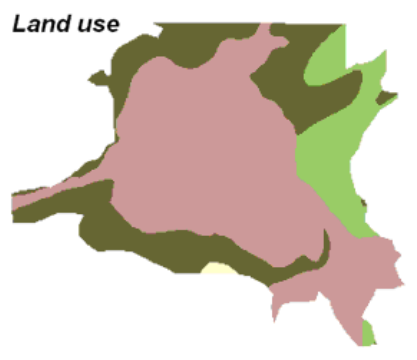

Flow Accumulation

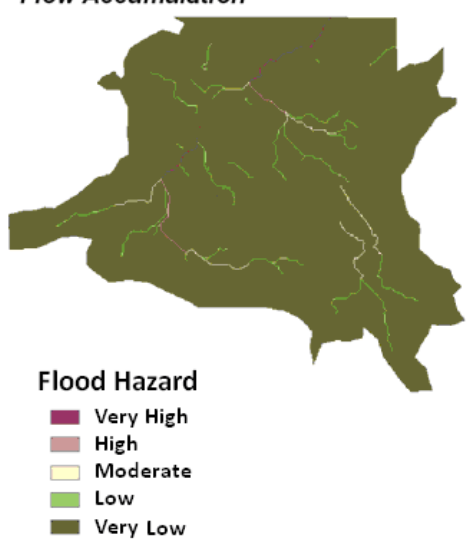

Figure 5 - Flood hazard maps for each factor. 


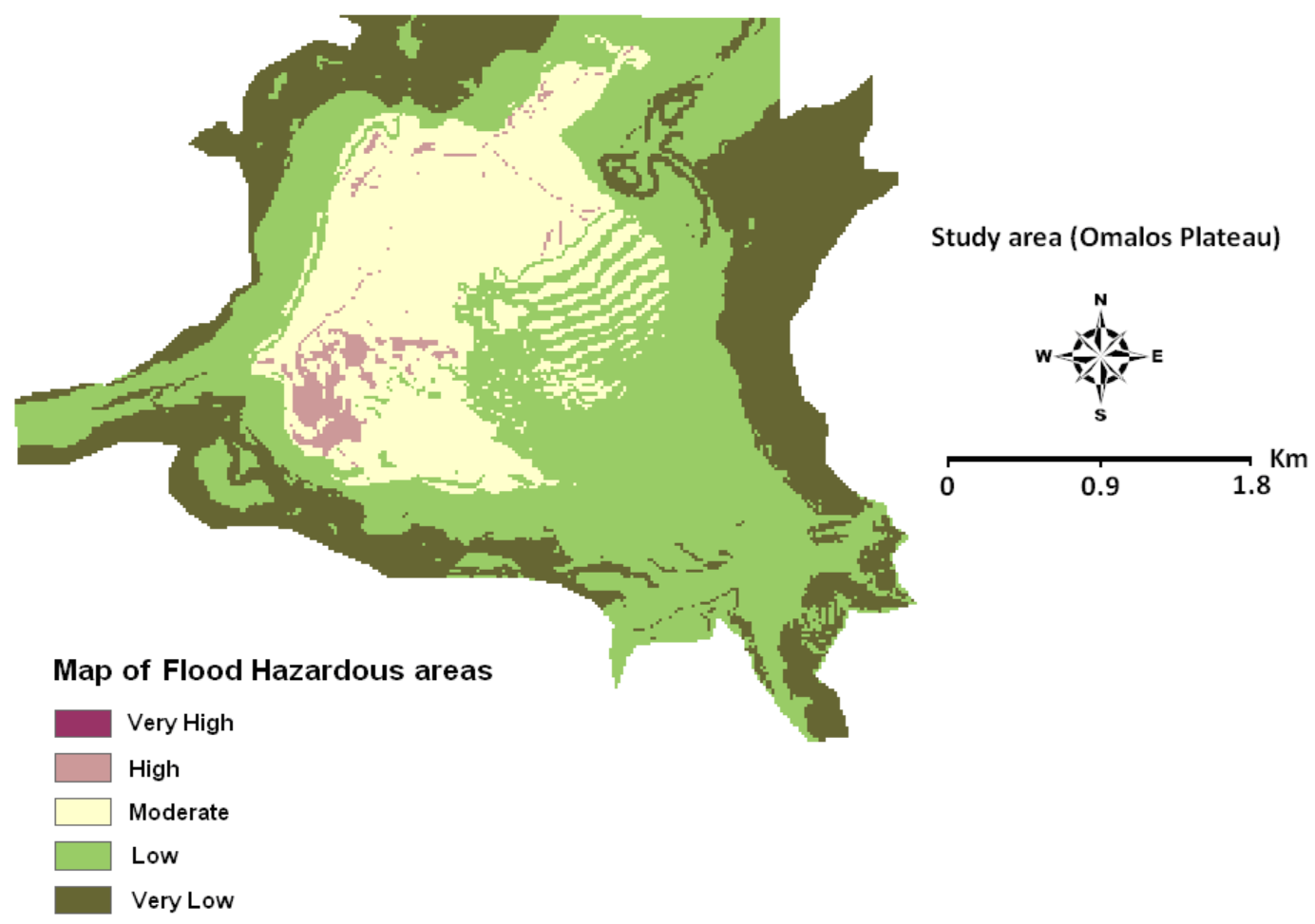

Figure 6 - Final flood hazardous map for the study area.

In answering this question the map of equipotential lines for an extended area of Omalos Plateau was created (Figure 7). This map was based on the groundwater level data from four wells in the Omalos Plateau. Figure 7 also describes the flow direction, perpendicular to the equipotential lines, and the existing faults in the region. According to this figure the direction of groundwater flow is north-west, through this flow direction groundwater encountered many large and small faults that direct groundwater in the north at Meskla and Agia springs (Figure 8). At this point it is very important to mention that: a) based on the groundwater level data, the aquifer in the extended area of the Omalos Plateau is shallow $(3-7 \mathrm{~m})$, b) the study area receives significant amounts of rainfall, fact that lead to a rapid recharging of groundwater resources, and c) the groundwater flow in the study area discharges through the Meskla and Agia springs. These springs supplies drinking water important settlements in the Prefecture of Chania.

Based on the above, the highly significant groundwater contamination risk in the study area of Omalos Plateau from any excessive use of agrochemicals through intensification of agricultural activity is obvious. Any deposition of contaminants such as nitrates in this area may have the final recipient of the springs Meskla and Agia in the center and north of the Prefecture of Chania, respectively.

The above results are confirmed by the results of previous studies where a tracing method was performed by the Institute of Geological and Mineral Exploration (IGME) in 1989 and 1987 in the Omalos Plateau (Knithakis 1993). Specifically, dye was poured into carbonate rocks of the Omalos Plateau at an altitude of 1050 meters to monitor the groundwater flow connection of this region with the springs discharge in the northern and northeastern part of the White Mountains. As a result, the poured dye was detected in many discharge springs of the Prefecture of Chania such as the Meskla and Agia. 


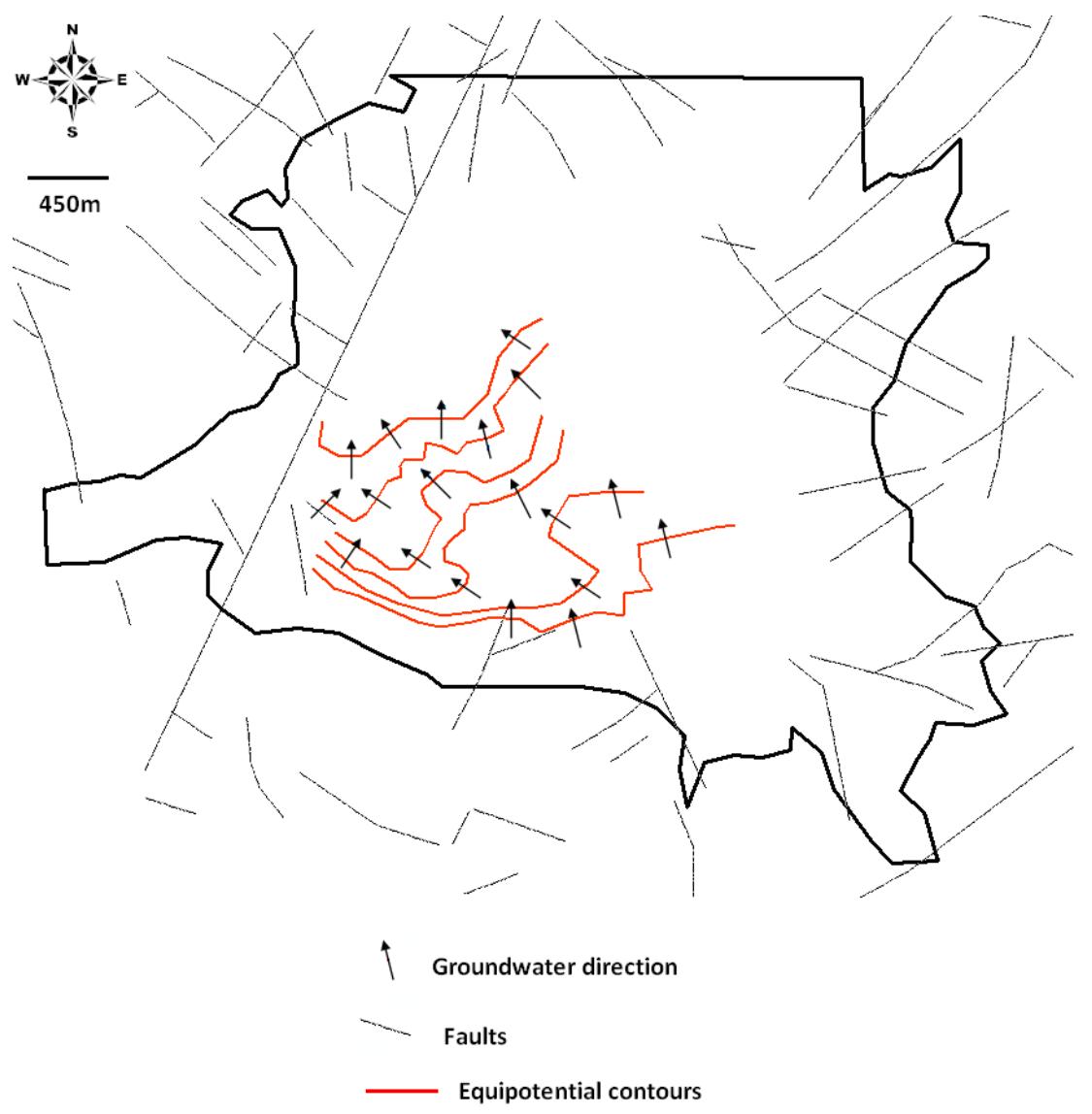

Figure 7 - Water table contour lines, faults and flow direction.
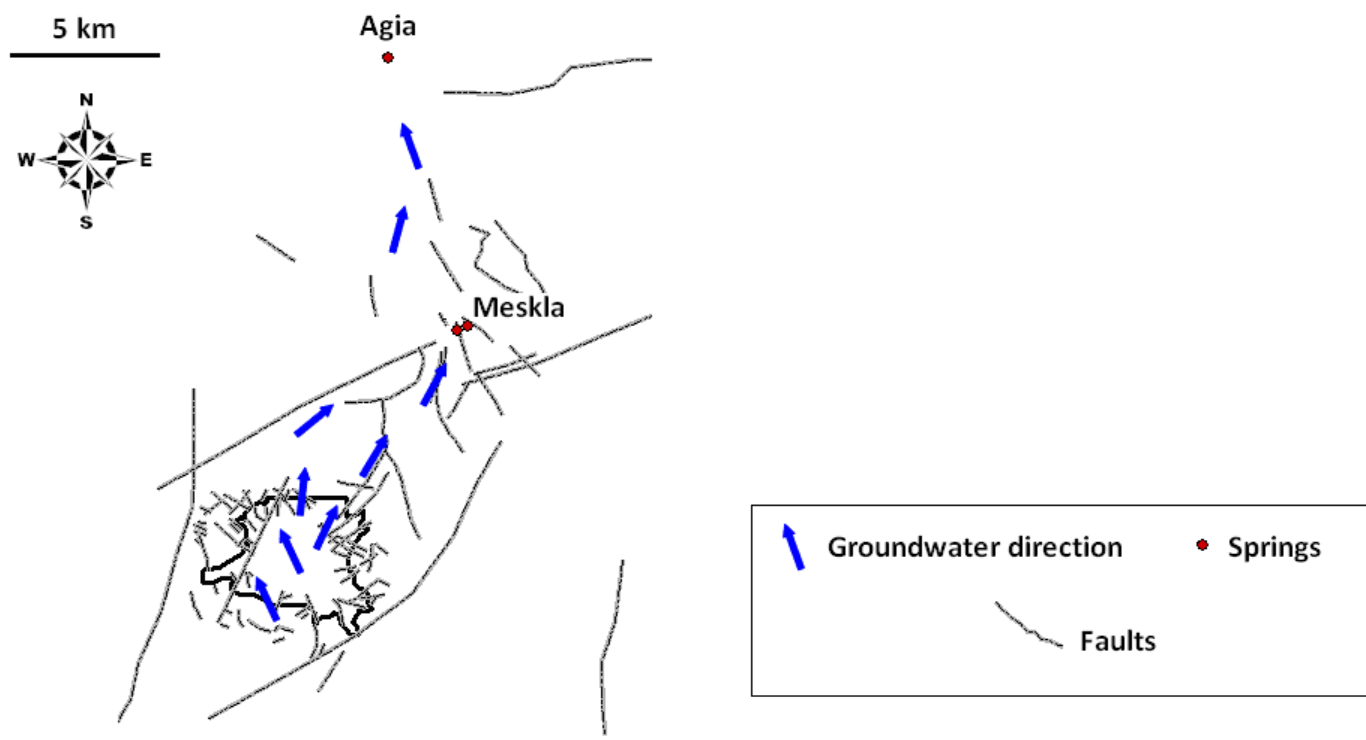

Figure 8 - Groundwater flow direction to springs.

$\underline{\text { XLVII, No } 2-729}$ 


\section{Conclusions}

This work presents a combined approach on flood and groundwater management. Specifically, in this work a method to evaluate the flood prone areas as well as a simple approach to estimate the groundwater contamination risk in the Omalos Plateau is presented. Based on the results of this study:

- The flood hazard phenomena in the study area can be characterized as high in south-western side of the Omalos Plateau, while in the rest parts as moderate to very low.

- The karstic aquifer of the Omalos Plateau can be characterized by many large faults and shallowness. All these features contribute to a high groundwater contamination risk in the Plateau from the increasing use of fertilizers and pesticides. Regarding the possible contamination in surrounding areas, especially the spring discharge of Meskla and Agia the groundwater hazard can be classified as very high.

It is very important to mention that the accuracy of groundwater flow direction in the study area should be verified using data from extra monitoring wells. The estimation of flood and the groundwater hazardous areas are fundamental components of a water management strategy. The proposed work could become a useful tool for the better organization of a management plan regarding the determination of the potential flooding areas and the areas of high groundwater contamination risk.

\section{References}

Ballesteros C.J.A., Eguibar M., Bodoque M.J., Diez-Herrero A., Stoffel M. and Gutierrez-Perez I. 2011. Estimating flash flood discharge in an ungauged mountain catchment with 2D hydrau lic models and dendrogeomorphic palaeostage indicators, Hydrological Processes, 25(6), 9 70-979.

Chiang Y.M. and Chang F.J. 2009. Integrating hydrometeorological information for rainfall-runoff modelling by artificial neural networks, Hydrological Processes, 23(11), 1650-1659.

Corine Land Cover 2006 for Greece, European Environmental Agency.

ESRI 2008. ArcView 9.2 User Manuals, Environmental System Research Institute, 380 New York Street, Redlands, CA, 92373 USA.

Hamdan A.D., Economou N., Kritikakis G., Andronikidis N., Manoutsoglou E., Vafidis A., Panagratis P. and Apostolidou G. 2012. 2D and 3D imaging of the metamorphic carbonates at Omalos plateau/polje, Crete, Greece by employing independent and joint inversion on resistivity and seismic data, International Journal of Speleology, 41, 199-209.

Knithakis M. 1993. Institute of Geological and Mineral Exploration (IGME), (in Greek).

Kourgialas N.N. and Karatzas G.P. 2011. Flood management and a GIS modelling method to asses s flood-hazard areas-a case study, Hydrological Sciences Journal, 56(2), 1-14.

Manfreda S., Sole A. and Fiorentino M. 2008. Can the basin morphology alone provide an insight into floodplain delineation? WIT Transactions on Ecology and the Environment, Vol. 118, 47-56, www.witpress.com

Morgan R.P.C. 2005. Soil erosion and conservation, Blackwell Publishing Ltd, Oxford UK.

Shaban A., Khawlie M. and Abdallah C. 2006. Use of remote sensing and GIS to determine recharge potential zones: the case of Occidental Lebanon, Hydrogeology Journal, 14(4), 433-443.

Smith R.M. 1986. Comparing traditional methods for selecting class Intervals on choropleth map, The Professional Geographer, 38(1), 62-67.

Wireman M., 2003. Characterization and Management of Ground Water Resources in Fractured rock Hydrogeologic Settings, Groundwater Monitoring and Remediation, 23, no. 3/ Summer 2003.

Yahaya S., Ahmad N. and Abdalla R.F. 2010. Multicriteria Analysis for Flood Vulnerable Areas i n Hadejia-Jama'are River Basin, Nigeria, European Journal of Scientific Research, 42(1), 7 $1-83$.

$\underline{\text { XLVII. No } 2-730}$ 